\title{
EDITORIAL
}

\section{Molecular Psychiatry: the highest Immediacy Index in the field of psychiatry}

Molecular Psychiatry (2006) 11, 324. doi:10.1038/sj.mp.4001820

The Journal Citation Report (JCR) division of Thomson Scientific, formerly known as the Institute for Scientific Information (ISI), has an extensive bibliographic database from which it generates indices of journal article citations. They release yearly updated figures, the most widely known being the Impact Factor, which is a measure of importance of scientific journals. Impact Factors have a substantial, albeit sometimes controversial, influence on the way published scientific research is perceived and evaluated.

The Impact Factor is calculated based on a 3-year period. For example, the 2004 Impact factor for a journal would be calculated as follows:

A No. of times articles published in 2001-2002 were cited in tracked journals during 2003,

$B \quad$ No. of articles published in 2001-2002.

Impact Factor $=A / B$.

Molecular Psychiatry has an Impact of 6.9, which is third in our field. Our Impact Factor increased more than a full point between 2003 and 2004, and we moved up from fourth to third in psychiatry in that time period. The question for us is then: if one were to look at the most recent data, would we actually be better than third in the field right now?

To address questions about tendencies that are more recent than those computed into the Impact Factor, Thomson Scientific created another perspective for journal evaluation and comparison, called the Immediacy Index. This is a measure of how topical and urgent the papers published by a journal are. The Immediacy Index is calculated by dividing the number of citations to articles published in a given year by the number of articles published in that year. Thomson Scientific states that ranking by Immediacy Index is useful when one wishes to find journals whose current articles are quickly cited, whether one's purpose is to change publication or editorial policy, or whether one is looking for an indication that a journal publishes currently active, or hot, articles.

We are very excited to report that our 2004 Immediacy Index is 2.135, which is by far the highest in the field (see Figure 1). It is also over four times higher than the average Immediacy Index of psychiatric journals, which is 0.481 . We would like to sincerely thank our authors, editorial board members, reviewers, and readers for this impressive accomplishment.

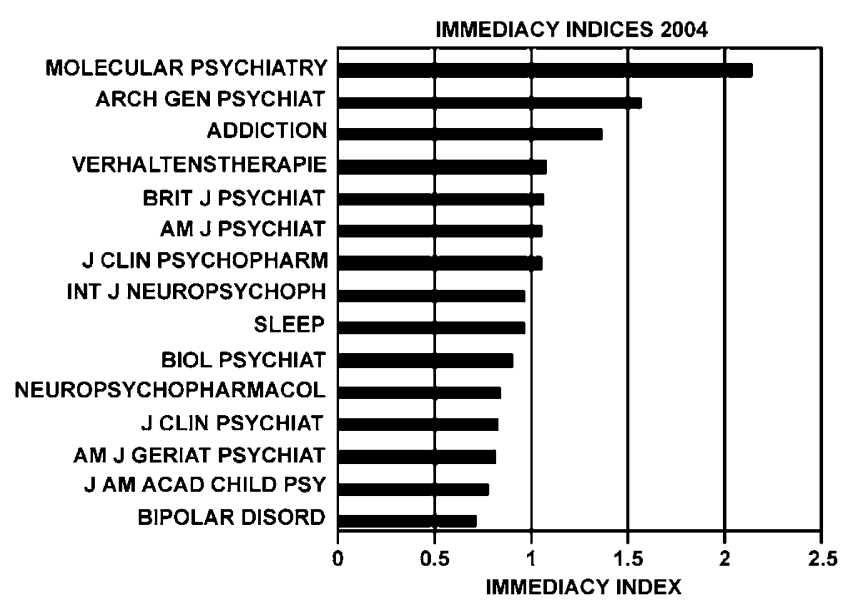

Figure 1 Immediacy indices 2004.

These data confirm the fact that we are now the journal of choice for publishing urgent new research. We are delighted that Molecular Psychiatry has undoubtedly become the home for key papers that are cited most rapidly and define hot areas of research.

J Licinio

UCLA, Department of Psychiatry and Behavioural Sciences, Los Angles, CA, USA E-mail: jlicinio@mednet.ucla.edu 